\title{
PREDICTING THE SEVERITY OF CIVIL WARS: AN ACTOR-CENTRIC APPROACH
}

\author{
NILS W. METTERNICH, ALTAF ALI, GOKHAN CIFLIKLI, GARETH LOMAX, KIT RICKARD, \\ AND SIGRID WEBER
}

\begin{abstract}
We introduce an actor-centric approach to predict the severity of conflict one month into the future. We argue that the prediction of conflict severity needs to focus on the actors that are responsible for conducting armed violence. Hence, we predict the severity of conflict in government-rebel organization dyads. Our predictors focus especially on rebel organization characteristics, behavior, and the conflict networks actors are embedded in. Our statistical learning approach relies on random forests to predict the severity of conflict. We demonstrate that our model performs especially well in distinguishing high levels of severity from very low levels, and yields better predictions that geography-based prediction models.
\end{abstract}

\section{INTRODUCTION}

Civil wars vary greatly in the degree to which they escalate and thereby affect civilians [46], regional stability, and global order [50]. For example, the extent to which conflicts force people to seek refuge abroad is consistently a function of its severity $[1,113]$ and its geographic scope [81]. We put forward a novel actor-based machine learning approach to predict the severity of conflict one month ahead to enable early warning facilities and contribute to the important and fast growing field of conflict prediction [26, 57].

While severity is a fundamental aspect of conflict dynamics [6], few attempts exist in the civil war literature to predict the variation in intensity of conflict $[17,4,63]$. The majority of forecasting efforts focus on the onset or occurrence of civil war $[116,62]$. Severity is much more at the center of approaches focusing on one-sided violence [120, 92, 97, 53, 28] and terrorism [34]. The limited focus on civil war severity in prediction studies is quite surprising, as the field of conflict prediction is growing rapidly [e.g. 58, 88, 101, 54, 117, 100, 43, 116, 51, 62, 9, 18, 27, 61, 86, 10, 30, 87].

We provide a novel contribution to the conflict prediction literature, as we explicitly focus on the prediction of actor behavior. While prediction approaches to inter-state conflict very much capture the behavior of actors [21] and its severity [32, 18], civil war predictions mostly concentrate on geographic locations (countries, regions, or grids) [60]. A geographic unit is often necessary in the context of civil war onset, as we cannot observe actors until they decide to fight the government. However, once the universe of actors is identified, there is an opportunity to make actor-based conflict predictions regarding the occurrence, duration, and severity of conflict [compare 82, 49, 44]. The advantage of actor-based predictions is that we can model the behavior of decision-making

Date: October 13, 2020 Version 1.03.

Paper prepared for the International Studies Association Annual Convention, March 27th - March 30th, 2019, Toronto. The authors acknowledge the helpful comments received at the Views Brown Bag Seminar (Department of Peace and Conflict Research, University of Uppsala). This research is funded by the Economic and Social Research Council (ES/L011506/1). 
organizations and rely on a broad theoretical literature to inform predictive feature selection and creation $[91,115,39,42,31,110,56,72]$. Hence, in our predictive models we include features that account for actors' characteristics, their past behavior, and interdependencies between rebel organizations. Compared to a geographic prediction approach, an actor-centric approach also has the advantage of only modeling the relevant set of units, which reduces the sparsity in the observed data. Grid-based forecasting approaches can entail many cells without any conflict activity, creating highly unbalanced prediction challenges [60].

\section{SEVERITY IN ARMED CONFLICT}

The interest in explaining the severity of armed conflicts can be traced to the very beginnings of quantitative conflict research. Richardson [95] already identified a power-law relationship between the frequency and severity of 'deadly quarrels'. Indeed power-law based explanations of severity gained renewed attention in conflict studies [96, 25] with applications to armed inter- and intrastate conflict $[2,11,99,112,48]$ and terrorist attacks $[34,33,90]$.

The work of Richardson [95] also inspired work to link the temporal dimension of conflict with severity. Already in the early 1960s Markov process driven relationships between severity of wars their duration were found [118]. This linkage between time and severity was further explored by Klingberg [71] who puts forward a breaking point theory in the context of interstate wars, demonstrating that severity is especially high at the beginning and that conflicts end if the first derivative of the cumulative density function of casualties approaches zero. Similarly, Voevodsky [114] shows temporal patterns that indicate that early stages in interstate wars see higher levels of violence.

Research projects collecting more fine-grained information on the behavior of states $[98,79,3,75]$ enabled a new generation of severity models that focused on the intensity of events and its actors $[102,14,12,13]$. Concepts of reciprocity [16], conflict-cooperation scales [106], and interdependencies [65] between actors are central to the behavioral actor-centric approaches. The actor-centric perspective on predicting severity also allowed for linkages to formal modeling approaches. For example, based on an expected utility model of war Bueno de Mesquita [22] predicts that casualties rise with an increasing utility of war [see also 23].

Compared to the inter-state war literature, civil war research on the severity of conflict is relatively small [24]. An initial study by [73] shows that severe civil wars are related to duration [compare 45], ethnic homogeneity, foreign assistance, and non-democracies. A particular focus in the civil war literature has been on economic development and studies have linked lower economic development [28], food insecurity [119], and economic inequality [77] with more severe conflicts. However, on the subnational level the link between economic development remains ambiguous. In a subnational study of FARC violence, [66] relate severe violence to departments with poverty, low growth, and state repression. But in Liberia, [64] demonstrate the opposite finding that rebels tend to target 'wealthy' locations and therefore find a negative relationship between poverty and severity of conflict, which is in line with [78] highlighting that civil wars are most severe when they take place in areas of oil and gas production in the context of secessionist conflicts. 


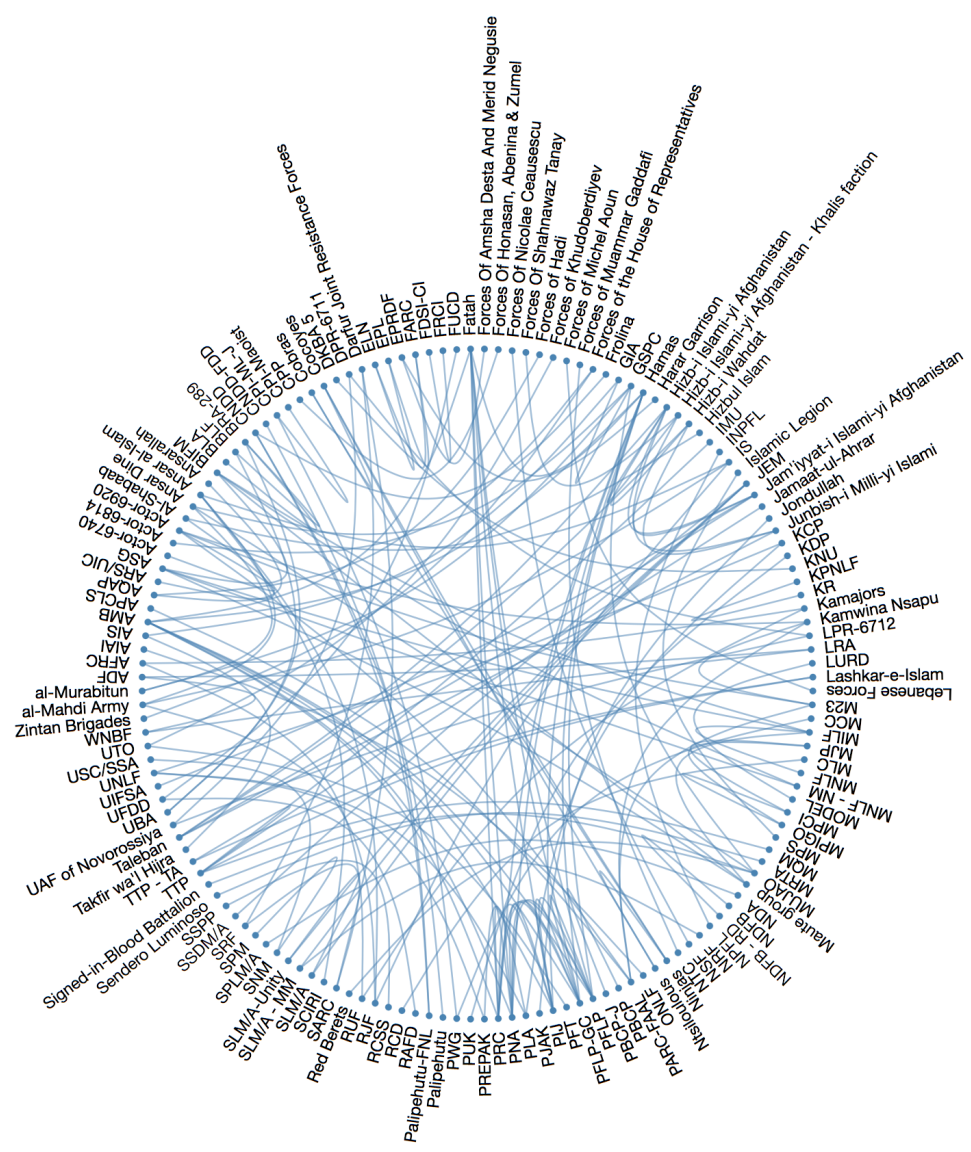

FiguRE 1. Visualization of 152 of 317 rebel organizations in the analysis (nodes) and their connection through fighting the same government (edges). This dependency structure is used to create spatial lags of all variables that measure actor characteristics and behavior.

Lacina's[73] finding that foreign assistance is linked to more severe conflicts has resulted in a broader agreement that third-party actors alone increase severity [107], but mediation and peacekeeping decrease battle-deaths [68, 8]. Furthermore, scholars have explored the role of economic sanctions that increase severity, whereas arms embargoes decrease severity [69]. Conventional weapon transfers seem to be related to more severe civil wars [85, 80].

Again following Lacina's [73] initial insights about ethnic homogeneity, ethnicity has been linked to the severity of civil wars in several ways. While Eck [45] demonstrates that ethnic conflicts generally have a higher risk of intensification, other research proposes that ethnic polarization especially affects severity at the beginning of conflicts [37] and shows that ethnic inequality is related to more severe conflicts [67]. From a more institutional perspective, Heger and Salehyan [59] argue that government coalitions led by small ethnic groups have the highest risk of conflict severity.

Finally, it is important to distinguish between escalation and severity in this context. In the context of international relations scholars, escalation describes the process by which political conflict or contest escalates to war $[52,104,94,36,74]$, whereas severity describes variation in armed conflict 
once it has escalated to this level. Theories of escalation of inter-state wars tend to focus on the path from contentious issues or low-level conflict to war, but are less interested in the variation of severity once inter-state conflicts have broken out [19, 103, 15]. Similarly, studies of repression and dissent [76, 89], as well as non-violent to violent protests [29] are more interested in the escalation, rather than the severity of the outcome.

\section{ACTOR CHARACTERISTICS, BEHAVIOR, AND DEPENDENCIES}

We present a prediction framework of severity that accounts for complex interactions between actor characteristics, behavior, and interdependencies. Actor characteristics form an important aspect of conflict dynamics. Capacity, resources, or strength have been systematically linked to the occurrence, duration, and severity of conflict [56, 110, 39, 35]. In our predictive framework, we account for actors characteristics, behavior, and interdependence by relying on data from UCDP GED (v.18.1) [109, 38] and PRIO-GRID (v.2.0) [111]. ${ }^{1}$

We measure actor characteristics by operationalizing variables that account for maximal observed features of severity that allows us to differentiate between stronger and weaker organizations, ${ }^{2}$ the time since the organization has started fighting the government, ${ }^{3}$ and the extent of transnational fighting events. ${ }^{4}$

We capture actor behavior by focusing on short run variation in past levels of severity inflicted by rebels on government and level of severity inflicted by government on rebels (lagged dependent variables). Furthermore, we measure the days affected by violent events in a month that involve the respective rebel organization, the number of violent events per month, the geographic scope of rebel operations (number of PRIO-GRIDS ${ }^{5}$ affected by violent events involving a rebel organization).

Finally, we account for the argument that rebel organizations do not act in isolation. Rebel organizations are likely to condition their behavior on the behavior of the government and those of other rebel organizations, which affects the severity of conflict $[24,83]$. Hence, we first include lagged measures of casualties that the government inflicts on the particular rebel organization and vice-versa. Second, the current literature demonstrates that rebel dependencies and configurations matter [e.g. 40, 39, 31]. Multi-actor setting also give rise to alliance and fragmentation dynamics $[5,7,47,42,105]$, which are argued to be associated with longer civil conflict duration [41, 31]. We account for interdependencies by creating spatial lags of all character and behavioral variables. To calculate the spatial lags we first calculate a dependency matrix that connects all actors that fight the same government. This connectivity matrix is visualized in Figure 1. We then multiply the dependency matrix with each of our features to account for interdependencies. All features are

\footnotetext{
${ }^{1}$ An alternative data source would be ACLED [93], but compared to UCDP GED, it does not yet allow for a global prediction framework.

${ }^{2}$ Maximum events per month involving the rebel organization, maximum days per month affected by events involving the rebel organization, past maximum level of severity inflicted by rebels on government, past maximum level of severity inflicted by government on rebels.

${ }^{3}$ Duration of months a rebel organization is fighting the government.

${ }^{4}$ Number of transnational events, which is measured as events outside of the main country of operation.

${ }^{5}$ PRIO-GRIDS are a standardized grid structure proposed by [111]. A PRIO-GRID is at the cell resolution of $0.5 \times$ 0.5 decimal degree. This corresponds to about $55 \times 55$ kilometers at the Equator
} 
temporally lagged before including them into the prediction models. Prediction models include 1-6 month time lags.

\section{Actor-Based Predicting of Battle-Related Deaths}

We predict battle-deaths 1-month ahead in a government-rebel organization dyad and distinguish between battle-deaths that rebel organizations inflict upon government forces and those that government forces inflict upon the rebels. ${ }^{6}$ Battle-deaths are measured at the monthly level and we distinguish between 4 levels of intensity: Level 0 (no battle-deaths), Level 1 (1-24 battle deaths), Level 2 (24-99 battle deaths), Level 3 (100+battle deaths). Relying on the UCDP-dyadic data (v.18.1), we define the universe of government-rebel organization dyads that are included in our study $(\mathrm{N}=317)$. For these government-rebel dyads we extract battle-deaths information from the event data base UCDP GED (v.18.1), which provides information on the time, location, and severity of an armed conflict event. Battle-deaths are measured by using the best estimate of battle deaths in a UCDP-GED event. ${ }^{7}$

We apply random forests to predict the categorical outcome variable. Random forest is a popular ensemble learning method [20] combining bagged trees with a randomized variable selection step to reduce variance. In political science, it has shown improvement over traditional statistical approaches $[108,70,86,84]$. We use the ranger [121] implementation in $\mathrm{R}$ statistical language for its computational efficiency. Using 79 features, we grow 500 trees and conduct a grid search to identify the top performing set of hyper-parameters: the number of randomly selected variables at each split (mtry=2,5,9) and tree splitting rule (split rule) while holding the minimum node size constant at 1 .

We separate the data into a training $(\mathrm{N}=18330, \mathrm{~T}=1989-2009)$ and test sample $(\mathrm{N}=6110$, $\mathrm{T}=2010-2017$ ). The training of the random forest is done by 10 -fold cross-validation without splitting observations across folds. Hence, all observations of rebel organization $i$ will be in fold $k$. We apply this cross-validation strategy, because we aim to learn about escalation dynamics across and not within rebel organizations. Model performance is assessed using the test sample. In Table 1 we provide sensitivity, specificity, precision, and balanced accuracy for both models. All models perform very well in identifying the Level 0 category, but especially sensitivity decreases with higher levels of severity. However, the relatively low sensitivity at higher levels of severity obstructs the observation that a) misclassification to closer severity levels is more likely than to distant ones and b) our models tend to do well in separating high severity from low severity events.

\section{Geography-Based Predicting of Battle-Related Deaths}

In order to test whether an actor-based approach is more effective in predicting conflict severity, we conduct an identical geography-based approach. This means that we construct the same indicators, but aggregated to the PRIO-Grid level instead of the actor level. Hence, as opposed to predicting the severity at the actor-level, we train the model to predict severity at the PRIO grid level and include lagged variables for whether actors were present in the grid in previous months.

\footnotetext{
${ }^{6}$ We also run all analysis for 6 -months ahead predictions. The results are presented in the appendix. The findings and conclusions drawn are the same.

${ }^{7}$ UCDP-GED differentiates between low, high, and best estimates for casualties.
} 
TABlE 1. Test set predictive performance indicators for casualties inflicted on the government by rebels (Reb $\rightarrow$ Gov) and casualties inflicted by the government on the rebels (Gov $\rightarrow$ Reb) for actor based models.

\begin{tabular}{|c|c|c|c|c|}
\hline & Level 0 & Level 1 & Level 2 & Level 3 \\
\hline \multicolumn{5}{|c|}{ 1-month ahead rebel $\rightarrow$ government models. } \\
\hline Sensitivity & 0.956 & 0.534 & 0.239 & 0.000 \\
\hline Specificity & 0.609 & 0.928 & 0.996 & 1.000 \\
\hline Precision & 0.899 & 0.616 & 0.653 & 0.000 \\
\hline Balanced Accuracy & 0.783 & 0.731 & 0.617 & 0.500 \\
\hline \multicolumn{5}{|c|}{ 1-month ahead government $\rightarrow$ rebel models. } \\
\hline Sensitivity & 0.960 & 0.435 & 0.292 & 0.000 \\
\hline Specificity & 0.551 & 0.937 & 0.981 & 1.000 \\
\hline Precision & 0.877 & 0.600 & 0.329 & 0.000 \\
\hline Balanced Accuracy & 0.756 & 0.686 & 0.636 & 0.500 \\
\hline
\end{tabular}

Again, we apply random forests to predict the categorical outcome variable of conflict intensity: Level 0 (no battle-deaths), Level 1 (1-24 battle deaths), Level 2 (24-99 battle deaths), Level 3 (100+battle deaths). We separate the data into a training $(\mathrm{N}=219519, \mathrm{~T}=1989-2009)$ and test sample $(\mathrm{N}=54879, \mathrm{~T}=2010-2017)$. As noted previously, there is greater sparsity in the data used in the geographic prediction approach because it includes all PRIO grids, many of which may not be relevant to the conflict actors. Other than the data structure, the modelling procedure is identical to that described above.

TABLE 2. Test set predictive performance indicators for casualties inflicted on the government by rebels (Reb $\rightarrow$ Gov) and casualties inflicted by the government on the rebels (Gov $\rightarrow$ Reb) for geography based models on the grid cell level.

\begin{tabular}{lcccc}
\hline \hline & Level 0 & Level 1 & Level 2 & Level 3 \\
\hline \multicolumn{4}{c}{ 1-month ahead rebel } & government models. \\
Sensitivity & 0.986 & 0.230 & 0.000 & 0.000 \\
Specificity & 0.244 & 0.982 & 1.000 & 1.000 \\
Precision & 0.906 & 0.604 & 0.000 & \\
Balanced Accuracy & 0.615 & 0.606 & 0.500 & 0.500 \\
\hline \multicolumn{5}{c}{ 1-month ahead government $\rightarrow$ rebel models. } \\
Sensitivity & 0.986 & 0.232 & 0.000 & 0.000 \\
Specificity & 0.246 & 0.981 & 1.000 & 1.000 \\
Precision & 0.906 & 0.605 & 0.000 & \\
Balanced Accuracy & 0.616 & 0.607 & 0.500 & 0.500 \\
\hline
\end{tabular}

Table 2 reports the results for the geographic approach. Similar to the actor-based approach reported in Table 1, both models perform well in identifying Level 0 category. In fact, the geographic approach is better at predicting Level 0, which is likely due to the sparsity of the data. However, the geographic models are less effective in correctly predicting higher levels of severity compared to actor-based models. They are less effective in correctly predicting Level 1 severity (1-24 battle deaths). For example, sensitivity is just 0.230 and 0.232 compared to 0.534 and 0.435 for models predicting causalities inflicted on the government by rebel and vice-versa, respectively. Difficulties in predicting the most severe levels are more pronounced in the geographic models. Looking once more at sensitivity, it decreases to 0 for Level 2 and Level 3 in both models, considerably worse than 

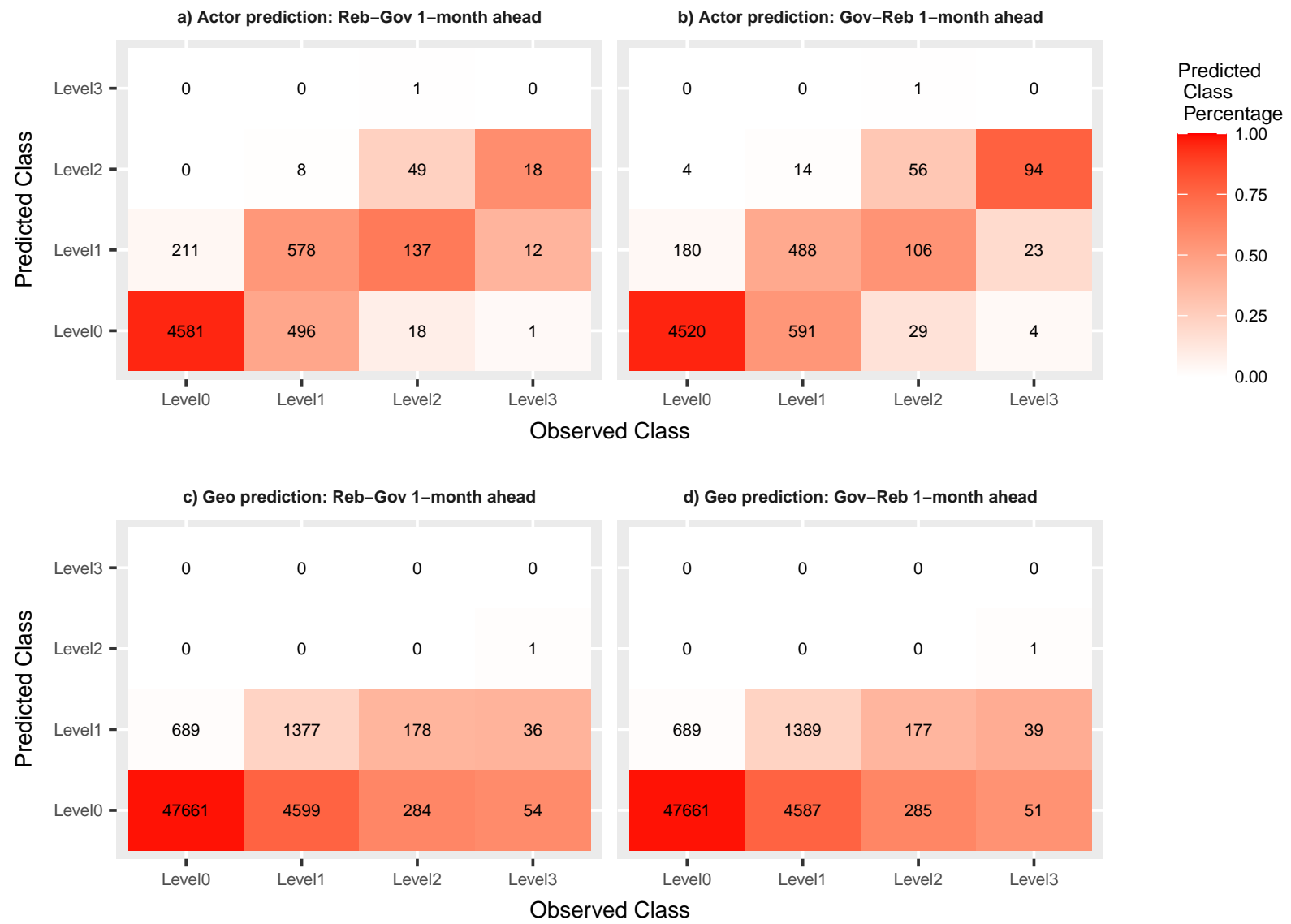

Figure 2. Confusion matrices for test-sample predictions. The first row (panels $a$ and $b$ ) panels pertain to actor-based models for casualties inflicted on the government by rebels (Reb $\rightarrow$ Gov) and casualties inflicted by the government on the rebels (Gov $\rightarrow$ Reb). The second row (panels $c$ and $d$ ) pertains to the geography-based models. Color shading refers to percentage of observed severity level months in the respective predicted categories. Numbers in cells refer to a count of observations that fall into this category. A perfect model would only have entries on the diagonal.

actor-based models which is 0 only in predicting Level 3 severity. Although actor-based models also struggle to predict Level 3 severity, they are more effective in distinguishing between Level 1 and Level 2 as indicated by higher sensitivity, specificity, precision, and balance accuracy. The results presented for both approaches indicate that the geographic approach under-performs in predicting the highest levels of severity, that is any level that surpasses 24 battle deaths (both levels 2 and 3). In the next section, we provide a further comparison between the actor-based and geography-based approaches.

\section{A SYSTEMATIC COMPARISON OF BOTH APPROACHES}

Figure 1 provides confusion matrices for the the actor-based (top row) and geography-based (bottom row) models. The figure once more emphasises the general trend for all models that they under-predict higher levels of severity. However, they provide important additional information 
on the false positives. Looking at panel $a$ for casualties inflicted on the government by rebels, we observe that predictions of high severity (Level 2) are associated with few false positives in regard to Level 0 . This means that if the model predicts a Level 2 severity month, there is a very low probability that no casualties will be observed in this month. Just one observation for both actorbased models has a predicted class of Level 3 when the observed class was Level 2. However, we see that the models under-predict severity, as opposed to failing to predict it altogether. For instance, in panel $a$ for casualties inflicted on the government by rebels, $58 \%$ (18/31) of observed Level 3 are classified as Level 2, 39\% (12/31) are classified as Level 1, and just 3\% (1/31) are classified as Level 0 . This pattern is similar in panel $b$ for casualties inflicted on the rebels by the government, although the percentage of Level 3 observed classes classified as Level 2 is higher $(78 \%){ }^{8}$

Similarly, when analyzing the classification of the 91 realized Level 3 months in the test set of rebel organization inflicting casualties on the government (panel $c$ ), we can report that the geography-based models are significantly worse at predicting higher levels of severity. For instance, only 1\% (1/91) of Level 3 are classified as Level 2 and 40\% (36/91) are classified at Level 1. Worryingly, the majority of realised Level 3 cases, $59 \%$ (54/91), are classified as Level 0 . The trend is almost identical for the classification of the 91 realized Level 3 months in the test set of government inflicting casualties on the rebel organisations (panel $d$ ). ${ }^{9}$ This trend is clearly visible by red shading across the different levels of severity. We can conclude that the actor-based models might not always predict the correct level of severity, but that higher levels of intensity have a lower probability of being classified as a Level 0 month than for the geography-based models. Furthermore, geography-based models are not only less likely to predict higher levels of severity, they are are also more prone to miss-classifying higher levels as expecting no observed casualties (Level 0).

The ability of the prediction models to separate months that experienced a certain level of severity from those that experienced a different level is visualized in Figure 3. For the models in both approaches, we provide a separation plot for each severity level. Separation plots were initially designed for binary outcomes [55], where realized observations (red bars) and unrealized observations (grey bars) are ranked according to their predicted probability (black line). A perfect separation occurs if any realized observation has a higher probability than any unrealized observation, which would leave all grey bars to the left and all red bars to the right of the separation plot. This concept can easily be generalized to a multi-categorical outcome [55], by providing separation plots for each category. For example, Figure $3 A$ pertains to actor-based model predicting government casualties inflicted by the rebels and provides separation plots for Level 0 (bottom), Level 1 (lower middle), Level 2 (upper middle), Level 3 (top). For all models we can observe that Level 0, Level 2 , and Level 3 months are fairly well separated and that the greatest challenge comes from Level 1 months (1-24 casualties). Going back to Figure 1, we can see that many realized Level 1 months are classified as Level 0 months, which questions the ability to correctly distinguish low severity months from no severity months in the context of an ongoing civil war. Figure 3 shows that the

\footnotetext{
${ }_{878 \%}(94 / 121)$ of observed Level 3 are classified as Level 2, 19\% (23/121) are classified as Level 1 and just 3\% (4/121) are classified as Level 0 .

${ }^{9} 1 \%(1 / 91)$ of observed Level 3 are classified as Level 2, 43\% (39/91) are classified as Level 1, and 56\% (51/91) are classified as Level 0.
} 


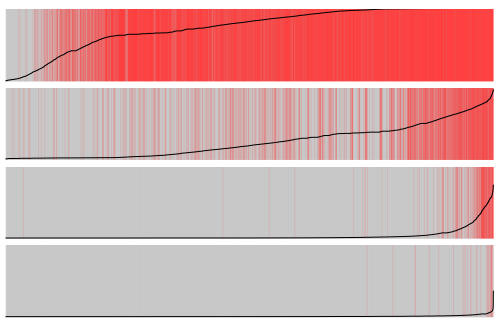

(A) Actor model: Reb $\rightarrow$ Gov

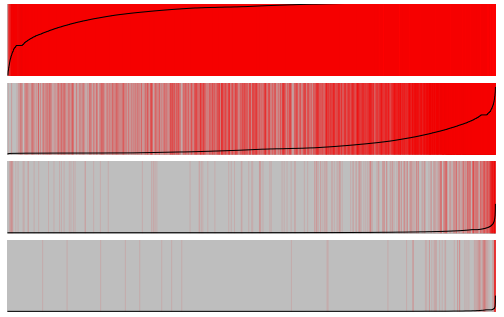

(c) Geo model: Reb $\rightarrow$ Gov

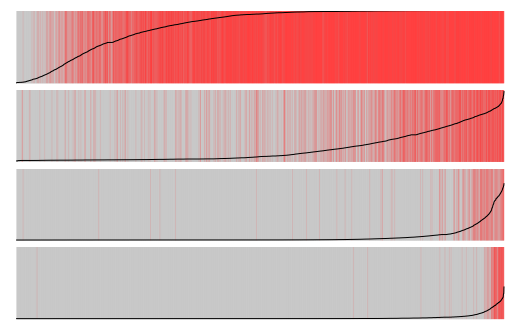

(B) Actor model: Gov $\rightarrow$ Reb

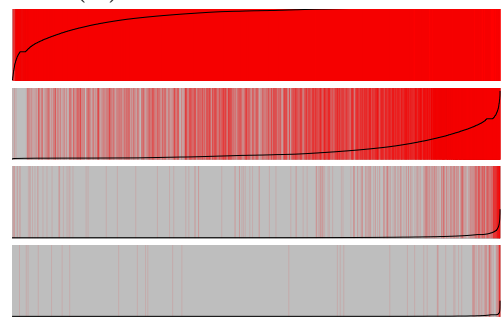

(D) Geo model: Gov $\rightarrow$ Reb

Figure 3. Separation plots for test-sample predictions. The top row (panels $A$ and $B$ ) pertain to actor-based predictions and the bottom row (panels $C$ and $D$ ) pertain to geography-based predictions. The left column (panels $A$ and $C$ ) are for casualties inflicted on the government by rebels (Reb $\rightarrow$ Gov) and the right column (Panels $B$ and $D$ ) are the same for casualties inflicted by the government on the rebels (Gov $\rightarrow$ Reb). In each panel, separation plots are provided for each level of severity. Level 0 (no battle-deaths = top), Level 1 (1-24 battle deaths $=$ upper middle), Level 2 (25-99 battle deaths $=$ lower middle), Level 3 (+100 battle deaths = bottom).

actor-based models are more effective in correctly predicting (i.e. separating) levels of severity, which is particularly visible for prediction of Level 1 severity (1-24 casualties).

\section{Global fatality comparison}

An interesting question is how the underprediction of the actor and geographic models translates into fatality estimates, especially because the escalation levels on the actor level are naturally higher than on the grid level. Hence, for each observed and predicted observation on the actor and grid level, we assign fatalities to escalation levels. For each observation and prediction, we draw from the underlying fatality distribution at each level for both the grid and actor level. From 1000 draws, we are then able to sum fatalities at the global monthly level for predicted and observed levels, both for the actor and grid model. Focusing on the difference between observed and predicted values, we compare the actor and geographic models in relation to fatalities inflicted on governments and the rebel organizations. The global fatality comparisons in Figure 4 shows that the actor model (red) underpredicts fatalities, but to a lesser degree than the geographic model (blue). This difference is particularly pronounced in the fatalities inflicted on government forces, shown in the top panel. 


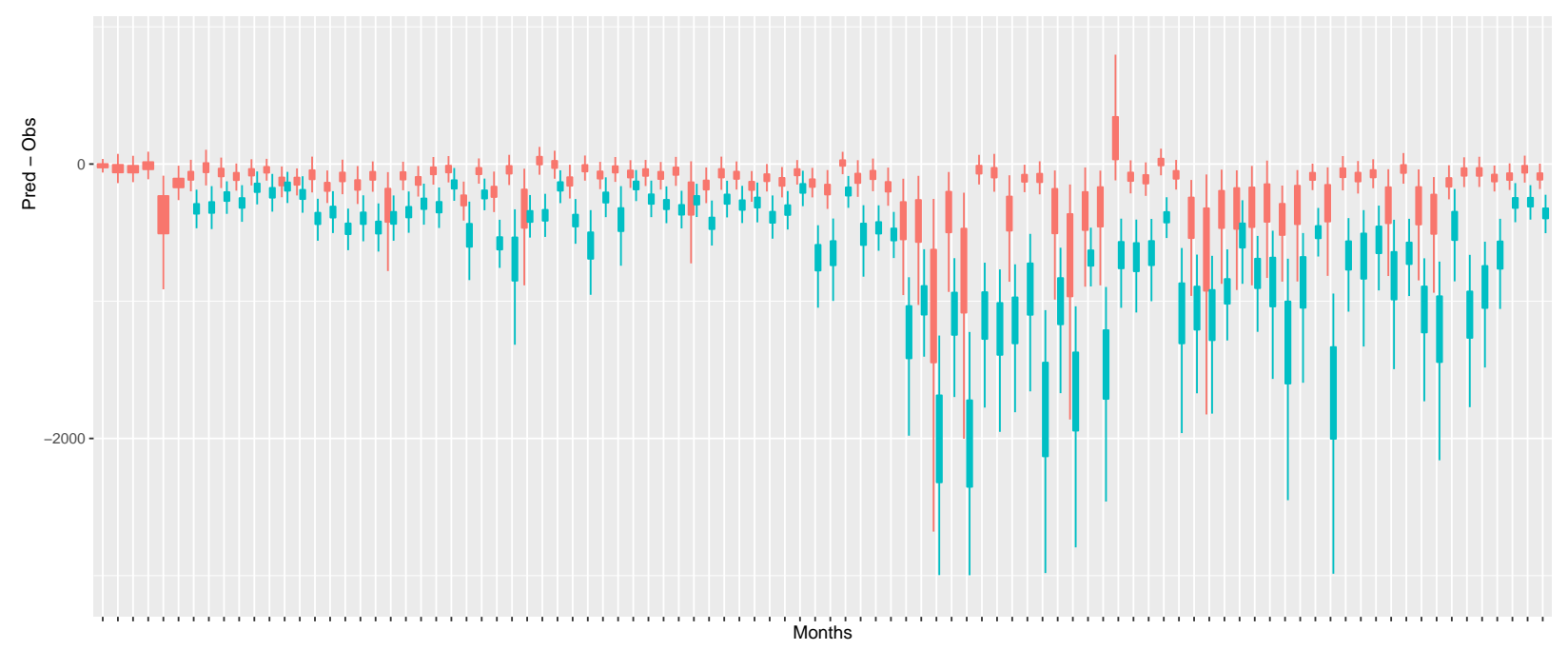

(A) Fatalities predicted-observed: Reb $\rightarrow$ Gov

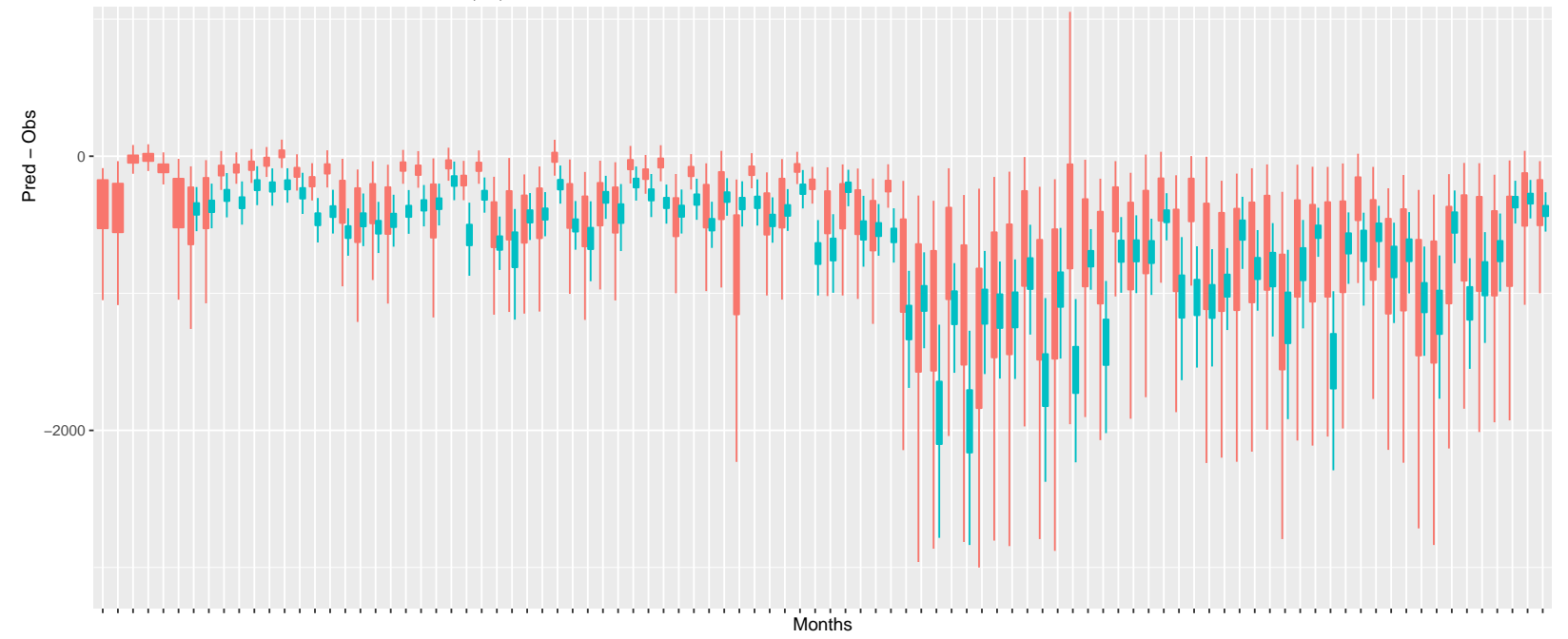

(в) Fatalities predicted-observed: Reb $\leftarrow$ Gov

FiguRE 4. Panels compare fatality estimates between predicted and observed values (y-axis) for actor (red) and grid (green) level model over months (x-axis) in the test sample.

\section{CASe illustration}

To demonstrate the performance of actor-based models in a more accessible and applied way, we use a case illustration on the actor level. Figure 5 displays predictions from the actor-based models for Al-Qaida and the Forces of Hadi in Yemen over time. The plots show the predicted probabilities for each severity level per time and actor. At each point in time, the model predicts the intensity level that is associated with the highest predicted probability. In the figure, correct predictions that correspond with the actually observed level of violence are marked in green, while incorrect predictions are displayed in red.

Overall, the two examples underline the strengths of actor-based models in separating Level 0 predictions (no violence) from Level 1 predictions (few violent events). This is particularly clear 

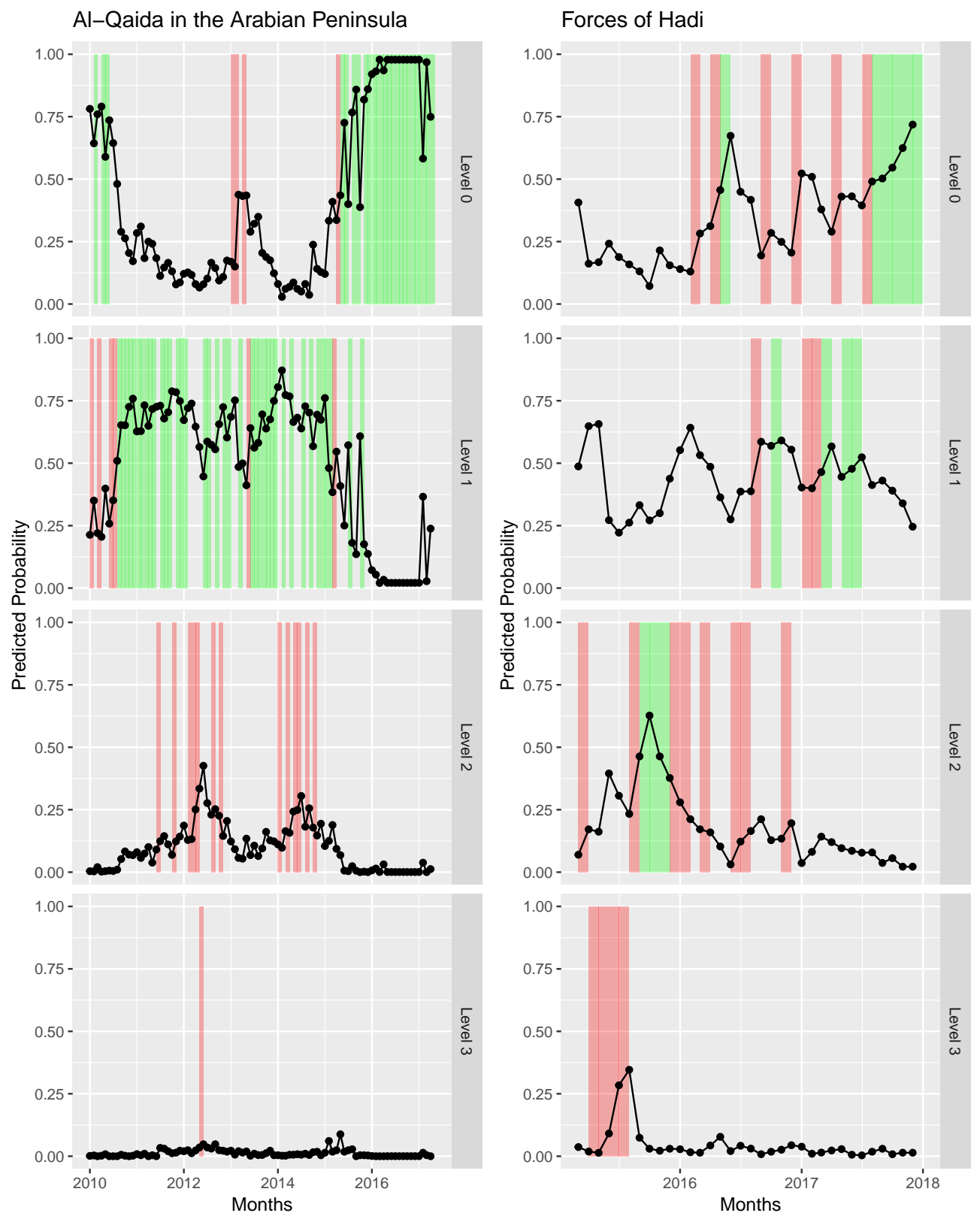

Figure 5. Test-sample severity predictions for two actors in Yemen. a) Al-Qaida in the Arabian Peninsula and b) Forces of Hadi. Green bars represent correct predictions, while red bars pertain to incorrect predictions. Panels pertain to 1month ahead model for casualties inflicted on the government by rebels (Reb $\rightarrow$ Gov). Level 0 (no battle-deaths = top), Level 1 (1-24 battle deaths = upper middle), Level 2 (25-99 battle deaths $=$ lower middle $)$, Level $3(+100$ battle deaths $=$ bottom $)$.

in the case of Al-Qaida on the left side with many correct (green) predictions for Level 0 and 1. The visualization also demonstrates that with increasing intensity it becomes difficult to correctly predict levels of battle-related deaths. 


\section{CONCLUSION}

In this paper, we provide an actor-centric approach to the prediction of civil war severity by focusing on the rebel-government dyad. We distinguish between severity of armed violence the government inflicts on rebel organizations and which the rebel organizations inflict on the government forces. These levels of severity are predicted at the monthly level with 1-month and 6-month ahead random forest models. Using features that relate to the rebel organization characteristics, behavior, and the interdependencies between organization, we are able to perform especially well in separating high levels of battle related deaths from months with no battle-related deaths being recorded. The main challenge that our predictive models face is to distinguish between low and no severity months, but this might not be surprising in the context of an ongoing civil war.

We believe that an actor-centric prediction approach is especially useful in the context of civil war severity, duration, and termination as it focuses on the actual perpetrators of armed violence. However, when predicting the onset of new actors/conflicts or the geographic diffusion of violence, actor-centric approaches need to be integrated and supplemented by geographic approaches.

\section{REFERENCES}

[1] Prakash Adhikari. Conflict-induced displacement, understanding the causes of flight. American Journal of Political Science, 57(1):82-89, 2013.

[2] Jose Alvarez-Ramirez, Eduardo Rodriguez, and Rafael Urrea. Scale invariance in the 20032005 iraq conflict. Physica A: Statistical Mechanics and its Applications, 377(1):291-301, 2007.

[3] Edward Azar. The Conflict and Peace Data Bank (COPDAB) Project. Journal of Conflict Resolution, 24:143-152, 1980.

[4] Benjamin E Bagozzi. Forecasting civil conflict with zero-inflated count models. Civil Wars, 17(1):1-24, 2015.

[5] Kristin M. Bakke, Kathleen Gallagher Cunningham, and Lee J. M. Seymour. A plague of initials: Fragmentation, cohesion, and infighting in civil wars. Perspectives on Politics, 10(02):265-283, 2012.

[6] Laia Balcells and Stathis N Kalyvas. Does warfare matter? severity, duration, and outcomes of civil wars. Journal of Conflict Resolution, 58(8):1390-1418, 2014.

[7] Navin A. Bapat and Kanisha D. Bond. Alliances between militant groups. British Journal of Political Science, 42(04):793-824, 2012.

[8] Kyle Beardsley, David E Cunningham, and Peter B White. Mediation, peacekeeping, and the severity of civil war. Journal of Conflict Resolution, page 0022002718817092, 2018.

[9] Sam R Bell, David Cingranelli, Amanda Murdie, and Alper Caglayan. Coercion, capacity, and coordination: Predictors of political violence. Conflict Management and Peace Science, 30(3):240-262, 2013.

[10] Robert A Blair, Christopher Blattman, and Alexandra Hartman. Predicting local violence: Evidence from a panel survey in liberia. Journal of Peace Research, 54(2):298-312, 2017.

[11] Juan Camilo Bohorquez, Sean Gourley, Alexander R Dixon, Michael Spagat, and Neil F Johnson. Common ecology quantifies human insurgency. Nature, 462(7275):911, 2009. 
[12] Doug Bond, Joe Bond, Churl Oh, J. Craig Jenkins, and Charles L. Taylor. Integrated data for events analysis (IDEA): An event typology for automated events data development. Journal of Peace Research, 40(6):733-745, 2003.

[13] Joe Bond and Doug Bond. Panda codebook. cambridge, ma: The program on nonviolent sanctions and cultural survival. Weatherhead Center for International Affairs, Harvard University, 1995.

[14] Elizabeth Boschee, Jennifer Lautenschlager, Sean O Brien, Steve Shellman, James Starz, and Michael D. Ward. ICEWS Coded Event Data. Harvard Dataverse, V2, 2015.

[15] Alex Braithwaite and Douglas Lemke. Unpacking escalation. Conflict Management and Peace Science, 28(2):111-123, 2011.

[16] Patrick T Brandt, Michael Colaresi, and John R Freeman. The dynamics of reciprocity, accountability, and credibility. Journal of Conflict Resolution, 2008.

[17] Patrick T Brandt, John R Freeman, and Philip A Schrodt. Real time, time series forecasting of inter-and intra-state political conflict. Conflict Management and Peace Science, 28(1):41-64, 2011.

[18] Patrick T Brandt, John R Freeman, and Philip A Schrodt. Evaluating forecasts of political conflict dynamics. International Journal of Forecasting, 30(4):944-962, 2014.

[19] Michael Brecher. Crisis escalation: Model and findings. International Political Science Review, 17(2):215-230, 1996.

[20] Leo Breiman. Random forests. Machine Learning, 45(1):5-32, 2001.

[21] Stuart A Bremer. Dangerous dyads: Conditions affecting the likelihood of interstate war, 1816-1965. Journal of Conflict Resolution, 36(2):309-341, 1992.

[22] Bruce Bueno de Mesquita. The costs of war: a rational expectations approach. American Political Science Review, 77(2):347-357, 1983.

[23] Bruce Bueno de Mesquita, David Newman, and Alvin Rabushka. Forecasting political events: the future of hong kong. New Haven, A Spatial Game-Theoretical Analysis, 89, 1985.

[24] Christopher K Butler, David E Cunningham, and Scott Gates. Explaining civil war severity: A formal model and empirical analysis. 2017.

[25] Lars-Erik Cederman. Modeling the size of wars: from billiard balls to sandpiles. American Political science review, 97(1):135-150, 2003.

[26] Lars-Erik Cederman and Nils B Weidmann. Predicting armed conflict: Time to adjust our expectations? Science, 355(6324):474-476, 2017.

[27] Thomas Chadefaux. Early warning signals for war in the news. Journal of Peace Research, 51(1):5-18, 2014.

[28] Stephen Chaudoin, Zachary Peskowitz, and Christopher Stanton. Beyond zeroes and ones: The intensity and dynamics of civil conflict. Journal of Conflict Resolution, 61(1):56-83, 2017.

[29] Erica Chenoweth and Jay Ulfelder. Can structural conditions explain the onset of nonviolent uprisings? Journal of Conflict Resolution, 61(2):298-324, 2017.

[30] Daina Chiba and Kristian Skrede Gleditsch. The shape of things to come? expanding the inequality and grievance model for civil war forecasts with event data. Journal of Peace 
Research, 54(2):275-297, 2017.

[31] Fotini Christia. Alliance Formation in Civil War. Cambridge University Press, Cambridge, 2012.

[32] Claudio Cioffi-Revilla. On the likely magnitude, extent, and duration of an iraq-un war. Journal of Conflict Resolution, 35(3):387-411, 1991.

[33] Aaron Clauset, Ryan Woodard, et al. Estimating the historical and future probabilities of large terrorist events. The Annals of Applied Statistics, 7(4):1838-1865, 2013.

[34] Aaron Clauset, Maxwell Young, and Kristian Skrede Gleditsch. On the frequency of severe terrorist events. Journal of Conflict Resolution, 51(1):58-87, 2007.

[35] Govinda Clayton. Relative rebel strength and the onset and outcome of civil war mediation. Journal of Peace Research, 50(5):609-622, 2013.

[36] Michael P Colaresi and William R Thompson. Alliances, arms buildups and recurrent conflict: Testing a steps-to-war model. The Journal of Politics, 67(2):345-364, 2005.

[37] Stefano Costalli and Francesco Niccolo Moro. Ethnicity and strategy in the bosnian civil war: Explanations for the severity of violence in bosnian municipalities. Journal of Peace Research, 49(6):801-815, 2012.

[38] Mihai Croicu and Ralph Sundberg. UCDP GED Codebook version 18.1. Department of Peace and Conflict Research, Uppsala University, 2017.

[39] David Cunningham, Kristian Skrede Gleditsch, and Idean Salehyan. It takes two: A dyadic analysis of civil war duration and outcome. Journal of Conflict Resolution, 53(4):570-597, 2009 .

[40] David E. Cunningham. Veto players and civil war duration. American Journal of Political Science, 50(4):875-892, 2006.

[41] David E. Cunningham. Blocking resolution: How external states can prolong civil wars. Journal of Peace Research, 47(2):115-127, 2010.

[42] Kathleen Gallagher Cunningham, Kristin M. Bakke, and Lee J. M. Seymour. Shirts today, skins tomorrow. Journal of Conflict Resolution, 56(1):67-93, 2012.

[43] Bruce Bueno De Mesquita. A new model for predicting policy choices preliminary tests. Conflict Management and Peace Science, 28(1):65-87, 2011.

[44] Cassy Dorff, Max Gallop, and Shahryar Minhas. Networks of violence: Predicting conflict in nigeria. The Journal of Politics, 82(2):476-493, 2020.

[45] Kristine Eck. From armed conflict to war: Ethnic mobilization and conflict intensification. International Studies Quarterly, 53(2):369-388, 2009.

[46] Kristine Eck and Lisa Hultman. One-sided violence against civilians in war: Insights from new fatality data. Journal of Peace Research, 44(2):233-246, 2007.

[47] Hanne Fjelde and Desirée Nilsson. Rebels against rebels: Explaining violence between rebel groups. Journal of Conflict Resolution, 56(4):604-628, 2012.

[48] Jeffrey A Friedman. Using power laws to estimate conflict size. Journal of Conflict Resolution, 59(7):1216-1241, 2015.

[49] Emily Kalah Gade, Mohammed M Hafez, and Michael Gabbay. Fratricide in rebel movements: A network analysis of syrian militant infighting. Journal of Peace Research, page 
$0022343318806940,2019$.

[50] Scott Gates, Håvard Hegre, Håvard Mokleiv Nygård, and Håvard Strand. Development consequences of armed conflict. World Development, 40(9):1713-1722, 2012.

[51] Kristian Skrede Gleditsch and Michael D Ward. Forecasting is difficult, especially about the future: Using contentious issues to forecast interstate disputes. Journal of Peace Research, 50(1):17-31, 2013.

[52] Charles S Gochman and Russell J Leng. Realpolitik and the road to war: An analysis of attributes and behavior. International Studies Quarterly, 27(1):97-120, 1983.

[53] Benjamin E Goldsmith, Charles R Butcher, Dimitri Semenovich, and Arcot Sowmya. Forecasting the onset of genocide and politicide: Annual out-of-sample forecasts on a global dataset, 1988?2003. Journal of Peace Research, 50(4):437-452, 2013.

[54] Jack A. Goldstone, Robert H. Bates, David L. Epstein, Ted Robert Gurr, Michael B. Lustik, Monty G. Marshall, Jay Ulfelder, and Mark Woodward. A global model for forecasting political instability. American Journal of Political Science, 54(1):190-208, 2010.

[55] Brian D. Greenhill, Michael D. Ward, and Audrey Sacks. The separation plot: A new visual method for evaluating the fit of binary models. American Journal of Political Science, 55(4):991-1003, October 2011.

[56] J Michael Greig. Rebels at the gates: Civil war battle locations, movement, and openings for diplomacy. International Studies Quarterly, 59(4):680-693, 2015.

[57] Weisi Guo, Kristian Skrede Gleditsch, and Alan Wilson. Retool ai to forecast and limit wars. Nature, 562:331-333, 2018.

[58] Ted Robert Gurr and Mark Irving Lichbach. Forecasting internal conflict a competitive evaluation of empirical theories. Comparative Political Studies, 19(1):3-38, 1986.

[59] Lindsay Heger and Idean Salehyan. Ruthless rulers: Coalition size and the severity of civil conflict. International Studies Quarterly, 51(2):385-403, 2007.

[60] Håvard Hegre, Marie Allansson, Matthias Basedau, Michael Colaresi, Mihai Croicu, Hanne Fjelde, Frederick Hoyles, Lisa Hultman, Stina Högbladh, Remco Jansen, et al. Views: A political violence early-warning system. Journal of Peace Research, page 0022343319823860, 2019 .

[61] Håvard Hegre, Halvard Buhaug, Katherine V Calvin, Jonas Nordkvelle, Stephanie T Waldhoff, and Elisabeth Gilmore. Forecasting civil conflict along the shared socioeconomic pathways. Environmental Research Letters, 11(5):054002, 2016.

[62] Håvard Hegre, Joakim Karlsen, Håvard Mokleiv Nygård, Håvard Strand, and Henrik Urdal. Predicting armed conflict, 2010-2050. International Studies Quarterly, 57(2):250-270, 2013.

[63] Håvard Hegre, Håvard Mokleiv Nygård, and Ranveig Flaten Ræder. Evaluating the scope and intensity of the conflict trap: A dynamic simulation approach. Journal of Peace Research, 54(2):243-261, 2017.

[64] Håvard Hegre, Gudrun Østby, and Clionadh Raleigh. Poverty and civil war events: A disaggregated study of liberia. Journal of Conflict Resolution, 53(4):598-623, 2009.

[65] Peter D Hoff and Michael D Ward. Modeling dependencies in international relations networks. Political Analysis, 12(2):160-175, 2004. 
[66] Jennifer S Holmes, Sheila Amin Gutiérrez De Piñeres, and Kevin M Curtin. A subnational study of insurgency: Farc violence in the 1990s. Studies in Conflict \& Terrorism, 30(3):249$265,2007$.

[67] John D Huber and Laura Mayoral. Group inequality and the severity of civil conflict. Journal of Economic Growth, pages 1-41, 2019.

[68] Lisa Hultman, Jacob Kathman, and Megan Shannon. Beyond keeping peace: United nations effectiveness in the midst of fighting. American Political Science Review, 108(4):737-753, 2014.

[69] Lisa Hultman and Dursun Peksen. Successful or counterproductive coercion? the effect of international sanctions on conflict intensity. Journal of Conflict Resolution, 61(6):1315-1339, 2017.

[70] Zachary Jones and Fridolin Linder. Exploratory data analysis using random forests. In Prepared for the 73rd annual MPSA conference, 2015.

[71] Frank L. Klingberg. Predicting the termination of war: battle casualties and population losses. Journal of Conflict Resolution, 10(2):129-171, 1966.

[72] Peter Krause. Rebel power: Why national movements compete, fight, and win. Cornell University Press, 2017.

[73] Bethany Lacina. Explaining the severity of civil wars. Journal of Conflict Resolution, 50(2):276-289, 2006.

[74] Bahar Leventoğlu and Ahmer Tarar. Does private information lead to delay or war in crisis bargaining? International Studies Quarterly, 52(3):533-553, 2008.

[75] Songnian Li, Suzana Dragicevic, Francesc Antón Castro, Monika Sester, Stephan Winter, Arzu Coltekin, Christopher Pettit, Bin Jiang, James Haworth, Alfred Stein, et al. Geospatial big data handling theory and methods: A review and research challenges. ISPRS journal of Photogrammetry and Remote Sensing, 115:119-133, 2016.

[76] Mark Irving Lichbach. Deterrence or escalation? the puzzle of aggregate studies of repression and dissent. Journal of Conflict Resolution, 31(2):266-297, 1987.

[77] Lingyu Lu and Cameron G Thies. Economic grievance and the severity of civil war. Civil Wars, 13(3):215-231, 2011.

[78] Paivi Lujala. Deadly combat over natural resources: Gems, petroleum, drugs, and the severity of armed civil conflict. Journal of Conflict Resolution, 53(1):50-71, 2009.

[79] Charles McClelland. World Event/Interaction Survey:(WEIS), 1966-1978. Inter-university Consortium for Political and Social Research, 1978.

[80] Marius Mehrl and Paul W Thurner. Military technology and human loss in intrastate conflict: The conditional impact of arms imports. Journal of Conflict Resolution, page $0022002719893446,2020$.

[81] Erik Melander and Magnus Öberg. The threat of violence and forced migration: Geographical scope trumps intensity of fighting. Civil Wars, 9(2):156-173, 2007.

[82] Nils W. Metternich, Cassy Dorff, Max Gallop, Simon Weschle, and Michael D. Ward. Antigovernment networks in civil conflicts: How network structures affect conflictual behavior. American Journal of Political Science, 57(4):892-911, 2013. 
[83] Nils W Metternich and Julian Wucherpfennig. A network approach to rebel fighting durations in civil wars. 2019.

[84] Jacob M Montgomery and Santiago Olivella. Tree-based models for political science data. American Journal of Political Science, 62(3):729-744, 2018.

[85] Matthew Moore. Selling to both sides: The effects of major conventional weapons transfers on civil war severity and duration. International Interactions, 38(3):325-347, 2012.

[86] David Muchlinski, David Siroky, Jingrui He, and Matthew Kocher. Comparing random forest with logistic regression for predicting class-imbalanced civil war onset data. Political Analysis, 24(1):87-103, 122016.

[87] Hannes Mueller and Christopher Rauh. Reading between the lines: Prediction of political violence using newspaper text. American Political Science Review, 112(2):358-375, 2018.

[88] Sean P O'brien. Anticipating the good, the bad, and the ugly an early warning approach to conflict and instability analysis. Journal of Conflict Resolution, 46(6):791-811, 2002.

[89] Jan Henryk Pierskalla. Protest, deterrence, and escalation: The strategic calculus of government repression. Journal of Conflict Resolution, 54(1):117-145, 2010.

[90] Carla MA Pinto, A Mendes Lopes, and JA Tenreiro Machado. A review of power laws in real life phenomena. Communications in Nonlinear Science and Numerical Simulation, 17(9):3558-3578, 2012.

[91] Robert Powell. Bargaining theory and international conflict. Annual Review Political Science, $5: 1-30,2002$.

[92] Clionadh Raleigh. Violence against civilians: A disaggregated analysis. International Interactions, 38(4):462-481, 2012.

[93] Clionadh Raleigh, Andrew Linke, Håvard Hegre, and Joakim Karlsen. Introducing acled: An armed conflict location and event dataset: Special data feature. Journal of Peace Research, 47(5):651-660, 2010.

[94] Karen Rasler and William R Thompson. Explaining rivalry escalation to war: Space, position, and contiguity in the major power subsystem. International Studies Quarterly, 44(3):503-530, 2000.

[95] Lewis Fry Richardson. Statistics of deadly quarrels. Boxwood Press, Pittsburgh, PA, 1960.

[96] David C Roberts and Donald L Turcotte. Fractality and self-organized criticality of wars. Fractals, 6(04):351-357, 1998.

[97] Nicolas Rost. Will it happen again? on the possibility of forecasting the risk of genocide. Journal of Genocide Research, 15(1):41-67, 2013.

[98] Rudolph J. Rummel. Indicators of cross-national and international patterns. American Political Science Review, 63(1):127-147, March 1969.

[99] Adam Scharpf, Gerald Schneider, Anna Nöh, and Aaron Clauset. Forecasting the risk of extreme massacres in syria. European Review of International Studies, 1(2):50-68, 2014.

[100] Gerald Schneider, Nils Petter Gleditsch, and Sabine Carey. Forecasting in international relations: One quest, three approaches. Conflict Management and Peace Science, 28(1):5-14, 2011. 
[101] Philip A Schrodt. Forecasting conflict in the balkans using hidden markov models. In Programming for Peace, pages 161-184. Springer, 2006.

[102] Philip A Schrodt, Shannon G Davis, and Judith L Weddle. Political science: Keds - a program for the machine coding of event data. Social Science Computer Review, 12(4):561-587, 1994.

[103] Paul D Senese. Geographical proximity and issue salience: Their effects on the escalation of militarized interstate conflict. Conflict Management and Peace Science, 15(2):133-161, 1996.

[104] Paul D Senese and John A Vasquez. The steps to war: An empirical study. Princeton University Press, 2008.

[105] Lee JM Seymour. Why factions switch sides in civil wars: Rivalry, patronage, and realignment in sudan. International Security, 39(2):92-131, 2014.

[106] Stephen Shellman. Measuring the Intensity of Intranational Political Events Data: Two Interval-Like Scales. International Interactions, 30(2):109-141, April 2004.

[107] Zachary C Shirkey. When and how many: The effects of third party joining on casualties and duration in interstate wars. Journal of Peace Research, 49(2):321-334, 2012.

[108] David S Siroky et al. Navigating random forests and related advances in algorithmic modeling. Statistics Surveys, 3:147-163, 2009.

[109] Ralph Sundberg and Erik Melander. Introducing the ucdp georeferenced event dataset. Journal of Peace Research, 50(4):523-532, 2013.

[110] Jakana Thomas. Rewarding bad behavior: How governments respond to terrorism in civil war. American Journal of Political Science, 58(4):804-818, 2014.

[111] Andreas Forø Tollefsen, Håvard Strand, and Halvard Buhaug. Prio-grid: A unified spatial data structure. Journal of Peace Research, 49(2):363-374, 2012.

[112] Christoph Trinn. Konflikt und Komplexität: die Intensität innerstaatlicher Gewaltkonflikte in systemtheoretischer Perspektive. Springer, Berlin, 2015.

[113] Oguzhan Turkoglu and Thomas Chadefaux. Nowhere to go? why do some civil wars generate more refugees than others? International Interactions, pages 1-20, 2018.

[114] John Voevodsky. Quantitative Behavior of Warring Nations. The Journal of Psychology, 72(2):269-292, 1969.

[115] Barbara F. Walter. Bargaining failures and civil war. Annual Review of Political Science, 12:243-261, 2009.

[116] Michael D. Ward, Nils W. Metternich, Cassy L. Dorff, Max Gallop, Florian M. Hollenbach, Anna Schultz, and Simon Weschle. Learning from the past and stepping into the future: Toward a new generation of conflict prediction. International Studies Review, 15(4):473-490, 2013.

[117] Nils B. Weidmann and Michael D. Ward. Predicting conflict in space and time. Journal of Conflict Resolution, 54(6):883-901, 2010.

[118] Herbert K. Weiss. Stochastic Models for the Duration and Magnitude of a "Deadly Quarrel"?? Operations Research, 11(1):101-121, 1963.

[119] Gerdis Wischnath and Halvard Buhaug. Rice or riots: On food production and conflict severity across india. Political Geography, 43:6-15, 2014. 
[120] Reed M Wood. Rebel capability and strategic violence against civilians. Journal of Peace Research, 47(5):601-614, 2010.

[121] Marvin N. Wright and Andreas Ziegler. ranger: A fast implementation of random forests for high dimensional data in C++ and R. Journal of Statistical Software, 77(1):1-17, 2017. 


\section{Appendix A. Results For 6-Month PRedictions}

The following sections present the same figures and tables presented in the manuscript for actor and geographical models for 6-month ahead predictions. We do not interpret them in detail because the interpretation is similar to the models for 1-month ahead predictions.

TABLE 3. Test set predictive performance indicators for 6-month ahead models for casualties inflicted on the government by rebels (Reb $\rightarrow$ Gov) and casualties inflicted by the government on the rebels (Gov $\rightarrow$ Reb) for actor based models.

\begin{tabular}{|c|c|c|c|c|}
\hline & Level 0 & Level 1 & Level 2 & Level 3 \\
\hline \multicolumn{5}{|c|}{6 -month ahead rebel $\rightarrow$ government models. } \\
\hline Sensitivity & 0.960 & 0.416 & 0.459 & 0.000 \\
\hline Specificity & 0.505 & 0.944 & 0.994 & 1.000 \\
\hline Precision & 0.876 & 0.615 & 0.740 & \\
\hline Balanced Accuracy & 0.732 & 0.680 & 0.726 & 0.500 \\
\hline \multicolumn{5}{|c|}{6 -month ahead government $\rightarrow$ rebel models. } \\
\hline Sensitivity & 0.960 & 0.415 & 0.234 & 0.000 \\
\hline Specificity & 0.514 & 0.938 & 0.983 & 1.000 \\
\hline Precision & 0.868 & 0.593 & 0.310 & \\
\hline Balanced Accuracy & 0.737 & 0.677 & 0.609 & 0.500 \\
\hline
\end{tabular}

TABLE 4. Test set predictive performance indicators for 6-month ahead models for casualties inflicted on the government by rebels (Reb $\rightarrow$ Gov) and casualties inflicted by the government on the rebels (Gov $\rightarrow$ Reb) for geography based models on the grid cell level.

\begin{tabular}{lcccc}
\hline \hline & Level 0 & Level 1 & Level 2 & Level 3 \\
\hline \multicolumn{4}{c}{ 6-month ahead rebel } & government models. \\
Sensitivity & 0.984 & 0.219 & 0.000 & 0.000 \\
Specificity & 0.226 & 0.981 & 1.000 & 1.000 \\
Precision & 0.904 & 0.586 & 0.000 & \\
Balanced Accuracy & 0.605 & 0.600 & 0.500 & 0.500 \\
\hline \multicolumn{5}{c}{ 6-month ahead government $\rightarrow$ rebel models. } \\
Sensitivity & 0.984 & 0.219 & 0.000 & 0.000 \\
Specificity & 0.226 & 0.981 & 1.000 & 1.000 \\
Precision & 0.904 & 0.586 & 0.000 & \\
Balanced Accuracy & 0.605 & 0.600 & 0.500 & 0.500 \\
\hline
\end{tabular}



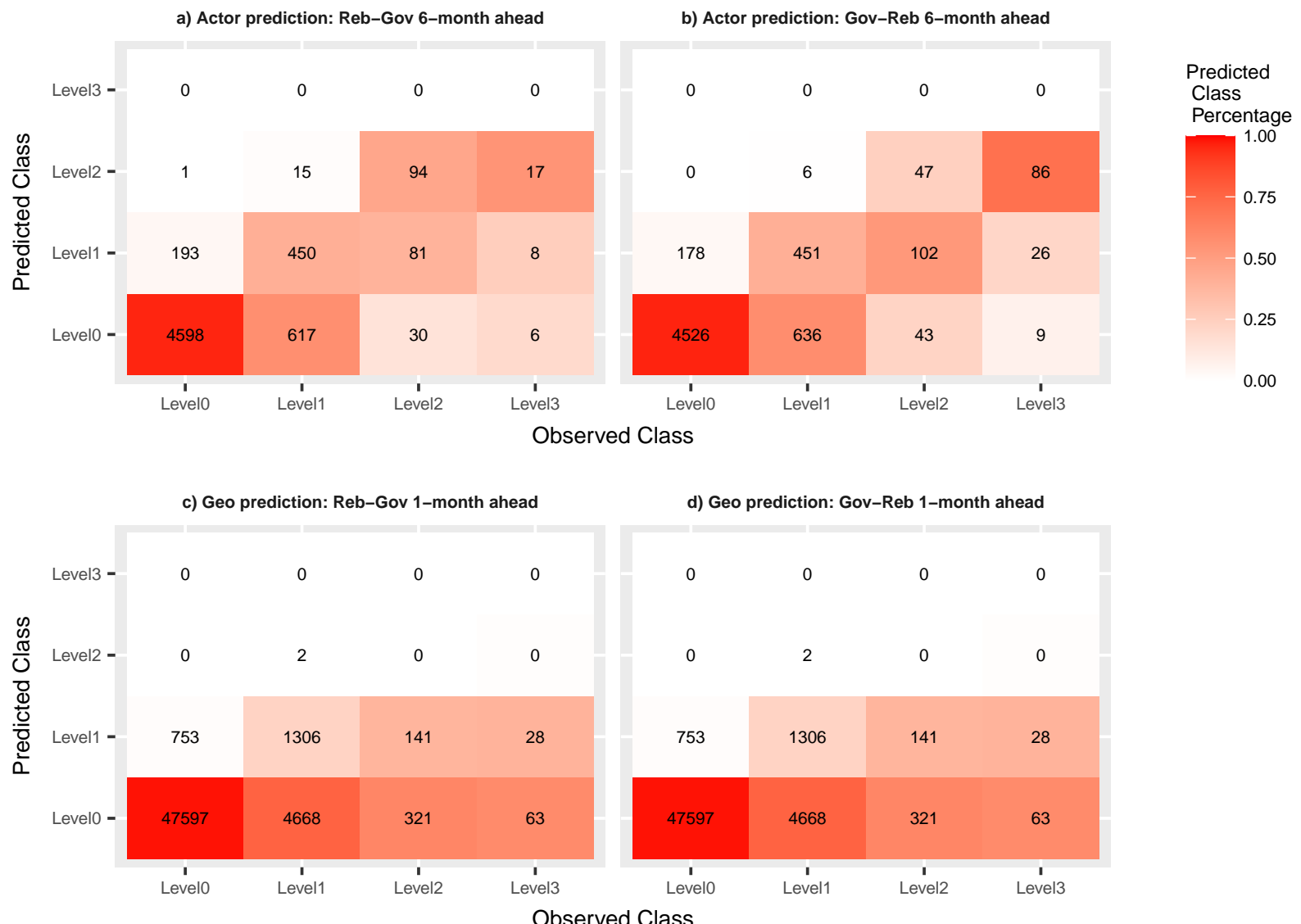

Figure 6. Confusion matrices for test-sample predictions on a 6 month basis. The first row (panels $a$ and $b$ ) panels pertain to actor-based models for casualties inflicted on the government by rebels (Reb $\rightarrow$ Gov) and casualties inflicted by the government on the rebels (Gov $\rightarrow$ Reb). The second row (panels $c$ and $d$ ) pertains to the geography-based models. Color shading refers to percentage of observed severity level months in the respective predicted categories. Numbers in cells refer to a count of observations that fall into this category. A perfect model would only have entries on the diagonal.

Nils W. Metternich: Department of Political Science

Current address: University College London, London, WC1H 9QU, UK

Email address: n.metternich@ucl.ac.uk

Altaf Ali: Department of Political Science

Current address: University College London, London, WC1H 9QU, UK

Email address: altaf.ali@ucl.ac.uk

Gokhan Ciflikli: Department of Methodology

Current address: London School of Economics and Political Science, London, WC2A 2AE, UK

Email address: g.ciflikli@lse.ac.uk

Gareth Lomax

Current address: Imperial College

Email address: gareth.lomax15@imperial.ac.uk

Kit Rickardi: Department of Political Science

Current address: University College London, London, WC1H 9QU, UK

Email address: christopher.rickard.14@ucl.ac.uk 


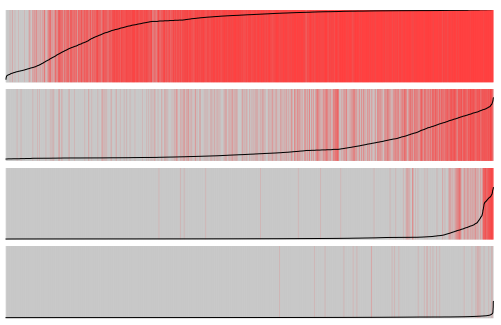

(A) Actor model: Reb $\rightarrow$ Gov

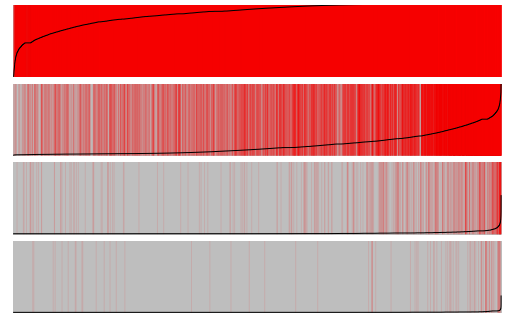

(c) Geo model: Reb $\rightarrow$ Gov

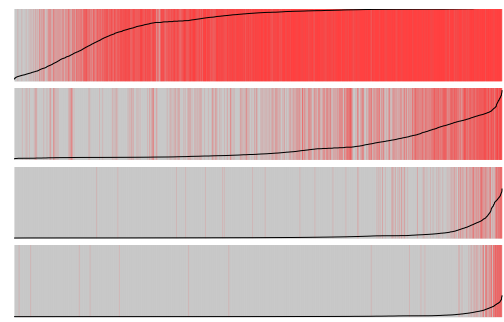

(B) Actor model: Gov $\rightarrow$ Reb

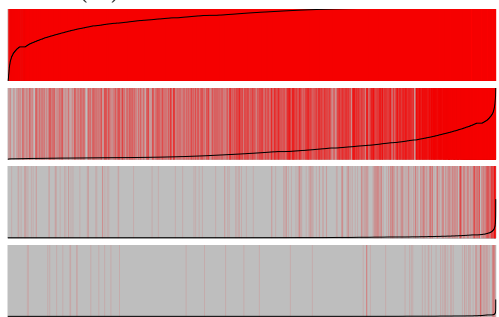

(D) Geo model: Gov $\rightarrow$ Reb

FiguRE 7. Separation plots for test-sample predictions for 6-month ahead. Panels $A$ pertain to actor-based predictions and panels $B$ to geography-based predictions for casualties inflicted on the government by rebels (Reb $\rightarrow$ Gov). Panels $C$ and $D$ are the same for casualties inflicted by the government on the rebels (Gov $\rightarrow$ Reb). In each panel, separation plots are provided for each level of severity. Level 0 (no battle-deaths = top), Level 1 (1-24 battle deaths = upper middle), Level 2 (25-99 battle deaths $=$ lower middle $)$, Level $3(+100$ battle deaths $=$ bottom $)$. 